\title{
Effects of climate change on heating and cooling degree days and potential energy demand in the household sector of China
}

\author{
Ying $\mathrm{Shi}^{1}{ }^{1}$ Xuejie $\mathrm{Gao}^{2, *}$, Ying $\mathrm{Xu}^{1}$, Filippo Giorgi ${ }^{3}$, Deliang Chen ${ }^{4}$ \\ ${ }^{1}$ National Climate Center, China Meteorological Administration, Zhongguancun Nandajie 46, Haidian District, \\ Beijing 100081, PR China \\ ${ }^{2}$ Climate Change Research Center, Institute of Atmospheric Sciences, Chinese Academy of Sciences, Huayanli 40, \\ Chaoyang District, Beijing 100029, PR China \\ ${ }^{3}$ The Abdus Salam International Centre for Theoretical Physics, PO Box 586, Trieste 34100, Italy \\ ${ }^{4}$ Department of Earth Sciences, University of Gothenburg, PO Box 460, 40530 Gothenburg, Sweden
}

\begin{abstract}
Future changes of heating and cooling degree days (HDD and CDD) in the 21st century over mainland China are projected with a regional climate model to investigate the potential effects of climate change on energy demand in the household sector. Validation of the model shows a good performance in reproducing the spatial distribution, magnitude and interannual variability of the present day HDD and CDD. Significant decreases in HDD and increases in CDD are projected under the warming. These are further weighted by population projections for a first-order assessment of future changes in energy demand. A larger decrease in population-weighted regional mean HDD compared to the increase in CDD is projected, indicating a decrease of about $15 \%$ in potential energy demand for different periods and scenarios in the future. In addition, the simulations show a marked spatial heterogeneity in the change in energy demand. Specifically, we find increases in both heating and cooling demand in parts of northern China due to the increased population there, an increase in cooling demand in the south and decreases in heating demand in the northernmost and western regions. Furthermore, a seasonal shift occurs, with increasing demand in summer and a decrease in winter. Finally, when the future reference temperatures for household heating and cooling change from standards currently used in China to values closer to those in Europe and the USA, potentially large increases in energy demand ( $80 \%)$ are expected, illustrating the importance of policy decisions concerning household heating and cooling.
\end{abstract}

KEY WORDS: Climate change - Regional climate model · Heating and cooling degree days · China

\section{INTRODUCTION}

Warming of the climate system is unequivocal, globally $\sim 0.85^{\circ} \mathrm{C}\left(0.65\right.$ to $\left.1.06^{\circ} \mathrm{C}\right)$ over the period of 1880 to 2012 (IPCC 2013). Continued emissions of greenhouse gases (GHGs) will cause further warming, with a projected temperature increase of 0.3 to $4.8^{\circ} \mathrm{C}$ by the end of the century $(2081-2100)$ relative to the present day (1986-2005) (IPCC 2013). Significant warming in the last decades has also occurred in

${ }^{*}$ Corresponding author: gaoxuejie@mail.iap.ac.cn
China, as in other parts of the world, at a larger rate than the global mean (e.g. Zhai \& Pan 2003, CCSNARCC 2011).

Changes in temperature strongly affect energy consumption for heating and cooling in the household sector, which accounts for nearly $20 \%$ of the total energy consumption in China (SSB 2013). Warmer climate conditions are expected to lead to a decrease in energy demand in winter and an increase in summer. The simplest way to estimate the

() The authors 2016. Open Access under Creative Commons by Attribution Licence. Use, distribution and reproduction are unrestricted. Authors and original publication must be credited.

Publisher: Inter-Research · www.int-res.com 
relationship between household energy consumption and temperature is through the concept of degree day, and specifically heating and cooling degree days (HDD and CDD, respectively, e.g. Quayle \& Diaz 1980). This concept has been widely used to estimate energy demand in climate change studies at both global and regional scales (e.g. Kadioğlu \& Şen 1999, Christenson et al. 2006, Isaac \& van Vuuren 2009, Wang et al. 2010, Rehman et al. 2011). Analysis of HDD and CDD has also been conducted for China, mostly for individual cities or small areas (Chen et al. 2007, Li et al. 2010, Tan et al. 2012). Limited studies have been carried out covering the whole country, in particular for investigating future changes in energy consumption under global warming conditions (Ren et al. 2009, You et al. 2014).

Regional climate models (RCMs) can be especially useful tools to study the response of HDD and CDD to global warming over China because they can simulate the regional climate detail associated with local complex topographical features and the unique weather and climate systems of the region (e.g. the East Asian monsoon) (e.g. Gao et al. 2001, 2012, Zhou \& Yu 2006, Ju et al. 2007, Li \& Zhou 2010, Yu et al. 2010). Therefore, in this study, we present an analysis of the future changes in HDD and CDD over China based on climate projections conducted with a high-resolution RCM under 2 representative concentration pathways (RCPs) (the high-level RCP8.5 and mid-level RCP4.5; Moss et al. 2010). We analyze the 21st century future periods 2046 to 2065 (mid-century) and 2080 to 2099 (end-of-century) with respect to the 'present day' period 1986 to 2005, and in particular, we focus on the mid-21st century under RCP4.5 and end of the century under RCP8.5 to present low and high ends of the range of future changes in our simulations.

As a further step in the study, the climate data are weighted by population density data at $0.5^{\circ}$ by $0.5^{\circ}$ degree resolution. This enables us to assess not only the total future energy demand in the household sector according to the climatological indicators (HDD and $\mathrm{CDD}$ ) but also its modulation by the present and projected population distribution. Such analysis can indeed provide important indications of significant spatial and seasonal shifts in energy demand within China, which is important information for the development of future energy management strategies and policies in the country. We stress that our study represents the first attempt in the literature to investigate changes in heating/cooling energy demand over China based on high-resolution climate and population data.

\section{DATA AND METHODS}

\subsection{Data}

The first step in our analysis is an assessment of the model performance when reproducing observed CDD and HDD over China under present-day conditions. The observational dataset employed for this purpose is CN05.1 developed by Wu \& Gao (2013), which is an augmentation of CN05 (Xu et al. 2009) including a greater number of station observations. The interpolation from station to grid data essentially follows the same approach used in generating the Climatic Research Unit dataset (CRU; New et al. 2002), whereby a gridded climatology is first calculated by thin-plate smoothing splines, and then a gridded anomaly derived via an angular weighting method is added to obtain the final data. CRU, CN05 and CN05.1 employ about 200, 750 and 2400 stations over China, respectively. Comparison of CN05 and CN05.1 with CRU shows basic similarities, with differences mostly in the areas where new and denser station data were introduced (e.g. western China and the Tibetan Plateau). Different spatial resolutions of $0.25^{\circ}, 0.5^{\circ}$ and $1^{\circ}$ are available in CN05.1, and here, we use the $0.5^{\circ}$ resolution to match the resolution of the RCM employed in the study. CN05 and the updated CN05.1 are becoming increasingly popular in model validation analyses over China (e.g. Gao et al. 2011, Wu et al. 2012, Guo \& Wang 2013, Sui et al. 2014).

The model simulations are conducted with the Abdus Salam International Centre for Theoretical Physics (ICTP) Regional Climate Model v.4, RegCM4 (Giorgi et al. 2012), driven by the global model BCC_CSM1.1 (Beijing Climate Center Climate System Model v.1.1; Wu et al. 2010, Xin et al. 2013). The RegCM4 domain covers continental China and surrounding areas with a grid spacing of $50 \mathrm{~km}$, and the simulation covers the period 1951-2005 for the present day (with observed GHG concentrations) and 2006-2099 for the future under the mid-level RCP4.5 and high-level RCP8.5 scenarios, respectively (Moss et al. 2010). A comparison of the RegCM4 and driving GCM simulations can be found in Gao et al. (2013), which shows remarkable improvements by RegCM4 in reproducing the present day climate over the region compared to the driving GCM. Specifically, the GCM simulation exhibits a general cold bias in the range of 1.0 to $2.5^{\circ} \mathrm{C}$ in eastern China and up to $10.0^{\circ} \mathrm{C}$ cold or warm biases in the complex topography areas of western China. Conversely, in the RegCM4 simulations, the temperature bias in 
eastern China decreases to values mostly within $\pm 1.0^{\circ} \mathrm{C}$, and only a cold bias of $\sim 2.5^{\circ} \mathrm{C}$ is found over the Tibetan Plateau. The model data are bilinearly interpolated into a regular $0.5^{\circ}$ by $0.5^{\circ}$ latitude-longitude grid to match the observation grid.

\subsection{Degree days}

A degree day is defined as the difference between mean daily temperature and a given reference temperature. For metrics designed to reflect the energy demand to heat/cool a building, the reference temperature is considered to be a human comfort temperature. While a reference temperature values of $18^{\circ} \mathrm{C}$ for heating and $22^{\circ} \mathrm{C}$ for cooling are widely used (e.g. Roltsch et al. 1999, Isaac \& van Vuuren 2009, Spinoni et al. 2015), these references vary across countries depending on the level of economic development, general characteristics of the buildings, climatic conditions, etc. In China, the current policy for the starting/ending dates of room heating (DSH and DEH), which can be dated back to the 1950s, states that only rooms in northern China are heated to a reference temperature of $18^{\circ} \mathrm{C}$, and the DSH and DEH are decided by the local governments in the cites and counties at the provincial level. Thus, tens of DSH and DEH may exist in the country.

The heating policy can be summarized as follows: (1) only areas with $>90 \mathrm{~d}$ of temperature $<5^{\circ} \mathrm{C}$ can be heated (to the reference value of $18^{\circ} \mathrm{C}$ ); (2) the heating starts/ends when the temperature is lower/ greater than $5^{\circ} \mathrm{C}$ for a continuous $5 \mathrm{~d}$ period in an annual cycle from 1 September to 31 August. Here, we use the above standards to define the areas and periods of heating for all provinces and municipalities and assume that these will remain unchanged in the future. (Note that the calculation of HDD follows the annual cycle from 1 September to 31 August instead of the calendar year.) Conversely, cooling days occur when the out-door air temperature exceeds $26^{\circ} \mathrm{C}$, following the Code for Design of Heating Ventilation and Air Conditioning (GB50019-2003) (MCPRC 2003). In this case, we assume that cooling lowers the room temperature to the reference value of $26^{\circ} \mathrm{C}$.

Thus, HDD and CDD in a given year are defined as follows:

$$
\left\{\begin{array}{l}
H D D=\sum_{i=1}^{n} r d\left(T_{b 1}-T_{i}\right) \quad(\text { if } \mathrm{DEH}-\mathrm{DSH}>90) \\
C D D=\sum_{i=1}^{n} r d\left(T_{i}-T_{b 2}\right)
\end{array}\right.
$$

where $\mathrm{n}$ is the number days in the year (365 or 366), $T_{i}$ is daily mean temperature for day $i, T_{b 1}$ and $T_{b 2}$ are the reference temperatures for heating $\left(18^{\circ} \mathrm{C}\right)$ and cooling $\left(26^{\circ} \mathrm{C}\right)$, respectively, and $r d$ is equal to 1 if $T_{i}$ is lower than $T_{b 1}$ (reference temperature for heating) or higher than $T_{b 2}$ (reference temperature for cooling) and is equal to 0 otherwise.

Note that the HDD (CDD) calculated following these policies are substantially lower (higher) than for policies adopted in Europe (Spinoni et al. 2015) and the USA (Roltsch et al. 1999) (typically with a reference temperature of $18^{\circ} \mathrm{C}$ for heating and $22^{\circ} \mathrm{C}$ for cooling and right after the temperature passes this threshold) and will likely change in the future following further economic development in China. For example, currently people in southern China often do not heat their rooms, although temperature may drop to $0^{\circ} \mathrm{C}$ in winter, mainly because the government, following the policy described above, does not provide subsidies for heating (MCPRC 2003, Chen et al. 2007). Thus, to test the importance of the reference temperature, we also present a sensitivity analysis of the HDD and CDD calculation using a reference temperature of $18^{\circ} \mathrm{C}$ for heating and $22^{\circ} \mathrm{C}$ for cooling (hereafter referred to as HDD18 and CDD22, respectively).

\subsection{Weighting by population}

Energy demand in the household sector is related to both climate and population density. Thus, in order to assess the impact of warming on energy demand, the geographically varying values of HDD and CDD are weighted by the corresponding population in the same half-degree grid box. The population weighted HDD and CDD, referred to as HDDP and CDDP, should thus describe more realistically the regional distribution of energy demand (e.g. Quayle \& Diaz 1980, Guttman 1983, Labriet et al. 2015). For present day and future population distribution, we use the dataset developed by the International Institute for Applied System Analysis (IIASA) (Riahi \& Nakicenovic 2007; GGI Scenario Database v.2.0, available at www.iiasa.ac.at/Research/GGI/DB/). This dataset provides population density on a $0.5^{\circ} \times 0.5^{\circ}$ (longitude-latitude) grid rather than at the country or regional level (e.g. Lutz et al. 2008, Chen \& Liu 2009, UNFPA 2010).

The distribution of present-day mean population over China from the IIASA dataset is presented in Fig. 1a. The population is unevenly distributed due to the complex natural features and economic condi- 

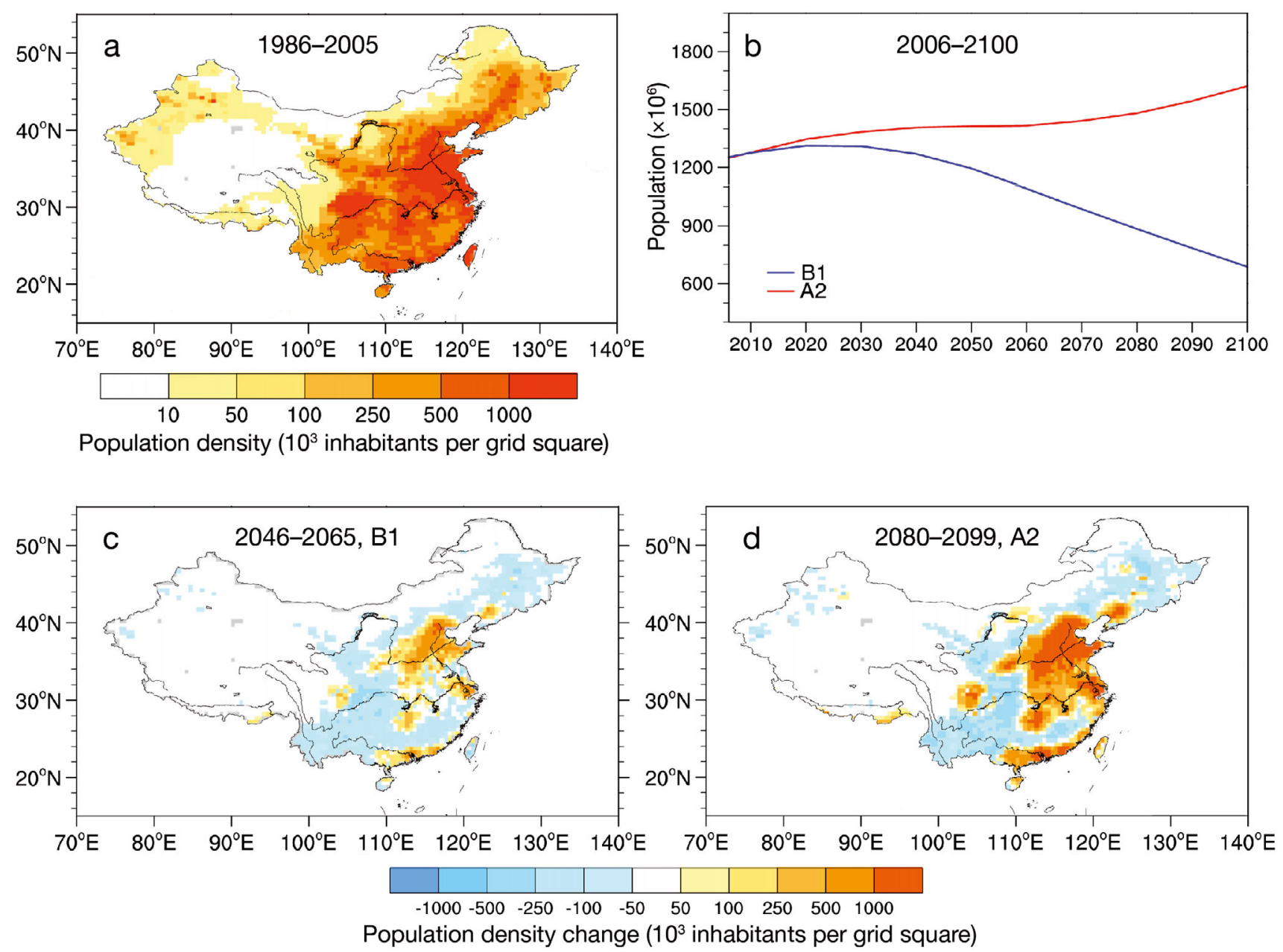

Fig. 1. Population density in China. (a) 'Present day' (1986-2005); (b) mean population in China for the period 2006-2100; (c) population change for the B1 mid 21st century (2046-2065); (d) population change for the A2 end of 21st century (2080-2099). Units are thousands per $0.5^{\circ} \times 0.5^{\circ}$ grid in (a), (c) and (d). Data are from the International Institute for Applied Systems Analysis (Riahi \& Nakicenovic 2007)

tions of the country, with higher density in the plains of southern and eastern China and lower density in the mountainous west, except the Sichuan Basin in the southwest.

Three scenarios of population growth are provided in the dataset: A2 for high, B2 for medium and B1 for low growth. We consider A2 for our high-end RCP8.5 scenario and B1 for the low-end RCP4.5. Future changes of total population in China are reported in Fig. 1b, showing continuous growth for A2 and growth followed by a decline in the B1. Population totals for China at the end of the 21st century in the $\mathrm{A} 2$ and B1 scenarios are 1.689 and 0.716 billion, respectively, slightly higher than the high-variant (1.554 billion) and low-variant ( 0.612 billion) of the latest United Nation population estimation (United
Nations 2015). The spatial distribution of the population changes in the mid 21st century under B1 and the end of the century under A2 are presented in Fig. 1c,d, respectively. The changes show similar patterns characterized by the shift of population towards the more developed regions of North China, the Yangtze River valley, Sichuan Basin and southern coastal areas.

The HDDP and CDDP in each of the $0.5^{\circ}$ grid box are normalized by the total population of China and then added up to obtain a total for its 31 provinces. We assume that, on average, each person needs the same amount of energy based on the HDD or CDD regardless of the individual economic conditions and life styles, an assumption that, admittedly, in some cases could be unrealistic. 


\section{RESULTS}

\subsection{Validation of the climate model}

Fig. 2 shows the HDD and CDD over China for the period 1986 to 2005 in the observations and simulations, along with the difference between the model simulation and observations (or model bias). RegCM4 generally reproduces the observed spatial distribution and magnitudes of both HDD and CDD over the region, with spatial correlation coefficients between simulated and observed data of 0.96 and 0.92 , respectively (both statistically significant at the $95 \%$ confidence level). However, some significant biases are also evident. The model underestimates HDD by $>500^{\circ} \mathrm{D}$ over parts of the Northeast and Northwest China (Fig. 2e) because of a warm model bias over high-latitude areas in the cold season (Zhang et al. 2008). HDD is somewhat overestimated over the Tibetan Plateau due to a cold bias there (Gao et al. 2013), but we note that the regions of maximum model error include only very sparse population (Fig. 1a).

Concerning CDD, the simulation captures the observed pattern of 0 values in the Tibetan Plateau and surrounding areas as well as the large values in eastern China and the basins of the Northwest (Fig. 2b,d). Over the most populated eastern China regions, the model shows a positive CDD bias (overestimation of up to $100^{\circ} \mathrm{D}$ ) in the northern portions, extending from North China to the Huanghuai area. Conversely, the CDD is underestimated over southern China (Fig. 2f). In general, the model shows a poorer performance in simulating the high-end warm events compared to the cold events, as reported by the previous studies of Zhang \& Shi (2012) and Ji \& Kang (2015).

Annual cycles of the regional mean HDD and CDD from observations and simulation over China are presented in Fig. 2g. Because China is mainly located in the mid and high latitudes, much larger HDD values are found than CDD. The HDD values are $>500^{\circ} \mathrm{D}$ during November to February, with a maximum in January, and drop to a few tens of ${ }^{\circ} \mathrm{D}$ in the summer months. The mean CDD over China is much smaller, with values around $10^{\circ} \mathrm{D}$ in June to August both in the observations and model simulation. The model captures the observed seasonal patterns and monthly values reasonably well, with overestimations of HDD in most months mainly due to the bias over the Tibetan Plateau and its surrounding areas (Fig. 2e).

Fig. 3 compares observed and simulated presentday interannual variability of HDD and CDD, as measured by the interannual standard deviation. Both for HDD and CDD, the model reproduces well the observed patterns of interannual variability, with pattern correlations of 0.92 and 0.90 , respectively. Also, the simulated magnitudes are in line with observations, with HDD maxima over northeast China and the Tibetan Plateau and CDD maxima over eastern and northwestern China. The most significant differences between the model simulation and observations include negative (positive) biases over the northern regions (Tibetan Plateau) for HDD and positive (negative) biases in northern China (southern China) for CDD, respectively.

We also calculated the trend in HDD and CDD during the present-day 1986-2005 period. When averaged over the whole China territory, the observations show a trend of $-106^{\circ} \mathrm{D}$ for HDD and $7^{\circ} \mathrm{D}$ for CDD, while the model simulates a mean trend of $-52^{\circ} \mathrm{D}$ and $1^{\circ} \mathrm{D}$, respectively. Therefore, the model captures the sign of the trends but underestimates the magnitude. The pattern correlations between the observed and simulated trends are 0.51 (statistically significant at the $95 \%$ confidence level) for HDD and 0.27 (not statistically significant) for CDD.

In summary, the validation analysis presented in this section shows that the model reproduces reasonably well the observed spatial pattern, annual cycles, and interannual variability of both HDD and CDD, although biases over some regions are present. The model also reproduces the spatial pattern of the trends in HDD but shows a poorer performance for the CDD trend.

\subsection{Future changes of temperature}

The spatial distribution of projected temperature changes in winter (December-January-February, DJF) and summer (June-July-August, JJA) for the RCP4.5 mid-21st century and RCP8.5 end of century are presented in Fig. 4. Annual changes of HDD and CDD are mostly affected by the temperature changes in DJF and JJA, respectively, and, as mentioned, the 2 time slices in Fig. 4 provide the lower and upper ends of the responses analyzed here. The temporal evolution of the regional mean temperature changes in the 21st century is also provided in the figure.

As shown in Fig. 4, substantial warming is found in both seasons and future periods. The warming is mostly in the range of 1.0 to $2.0^{\circ} \mathrm{C}$ in the mid-21st century under RCP4.5, except for a larger value of 2.0 to $2.5^{\circ} \mathrm{C}$ over the southern and eastern regions of the Tibetan Plateau in DJF (Fig. 4a,b). Regional mean changes of temperature in DJF and JJA averaged over China for the RCP4.5 mid-21st century are 1.5 

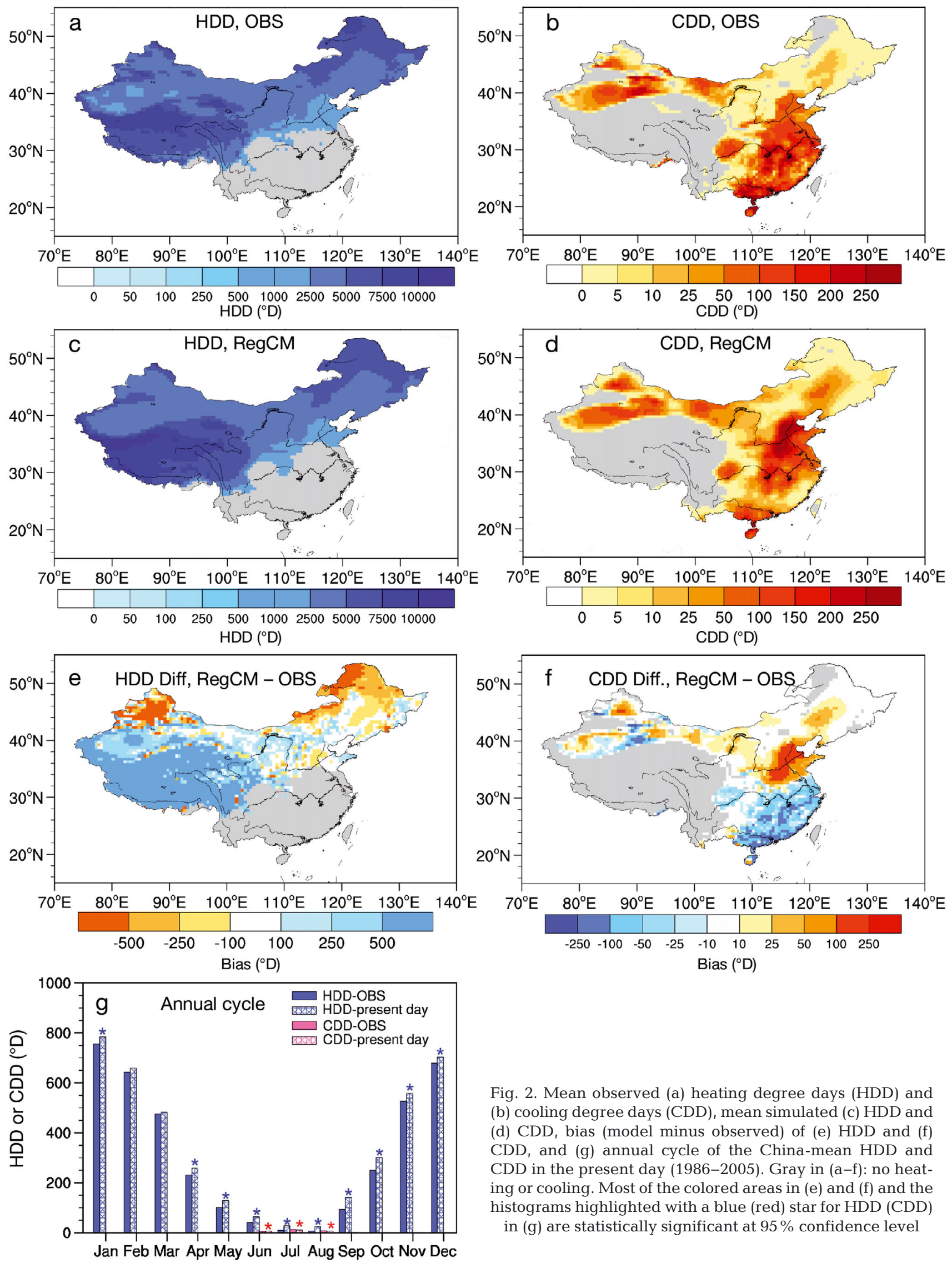

Fig. 2. Mean observed (a) heating degree days (HDD) and (b) cooling degree days (CDD), mean simulated (c) HDD and (d) CDD, bias (model minus observed) of (e) HDD and (f) CDD, and (g) annual cycle of the China-mean HDD and CDD in the present day (1986-2005). Gray in (a-f): no heating or cooling. Most of the colored areas in (e) and (f) and the histograms highlighted with a blue (red) star for HDD (CDD) in (g) are statistically significant at 95\% confidence level 

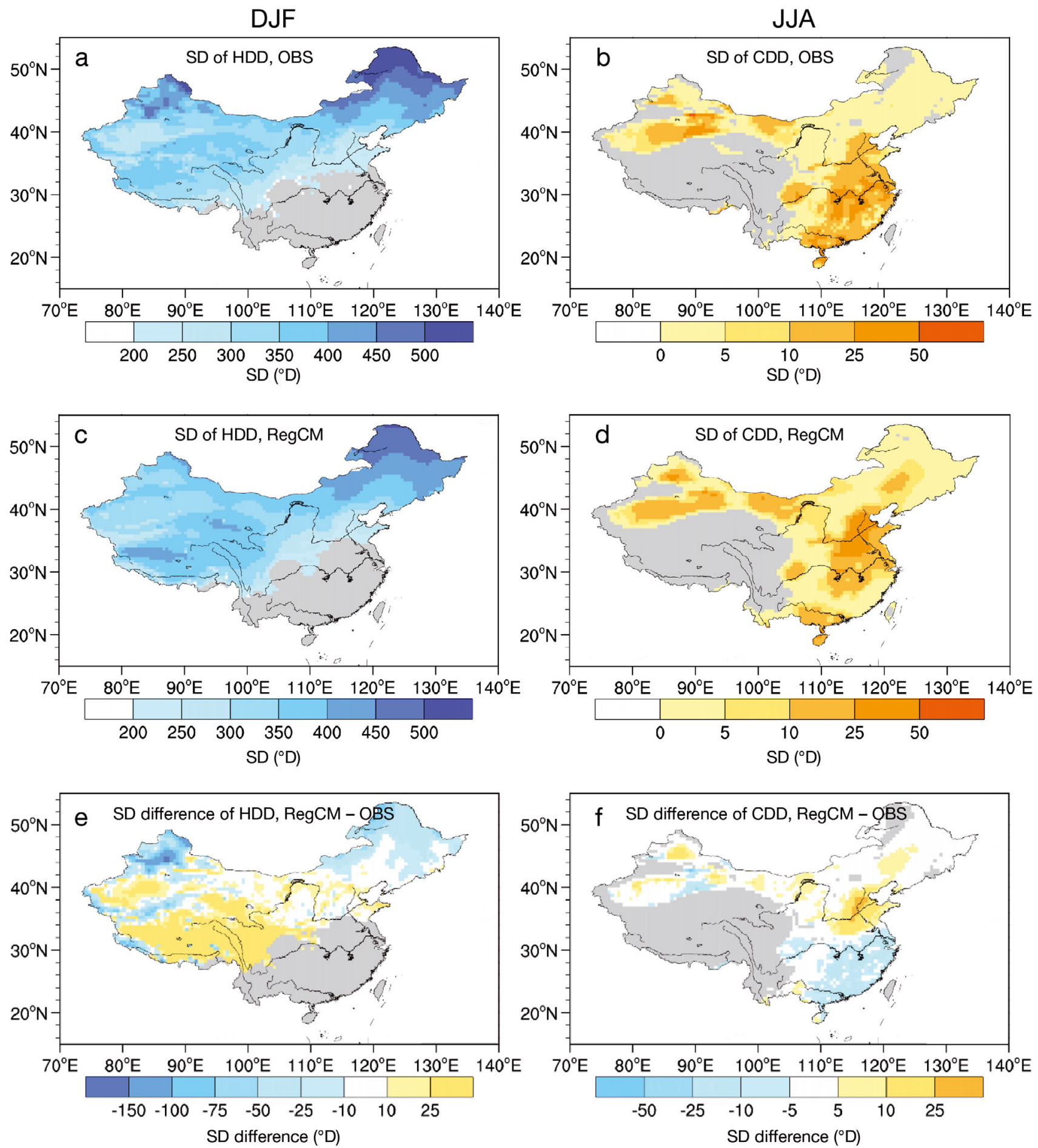

Fig. 3. Interannual variability as measured by the interannual standard deviation for the present day period (1986-2005). Observed (a) HDD and (b) CDD; simulated (c) HDD and (d) CDD; and simulated minus observed (e) HDD and (f) CDD. Gray in (a-f): no heating or cooling

and $1.4^{\circ} \mathrm{C}$, respectively. The warming is much more pronounced in the RCP8.5 end of century scenario, ranging from 2.5 to $6^{\circ} \mathrm{C}$ (Fig. $4 \mathrm{c}, \mathrm{d}$ ). The largest warming $\left(>5^{\circ} \mathrm{C}\right)$ is found in northeast China and the southern part of the Tibetan Plateau in DJF, along with the
Hetao area in northern China in JJA. Greater warming is found in DJF than JJA, with China mean values of 4.2 and $3.8^{\circ} \mathrm{C}$, respectively. In general, larger temperature increases in the high-latitude and high-elevation areas (Tibetan Plateau and the mountains) are 

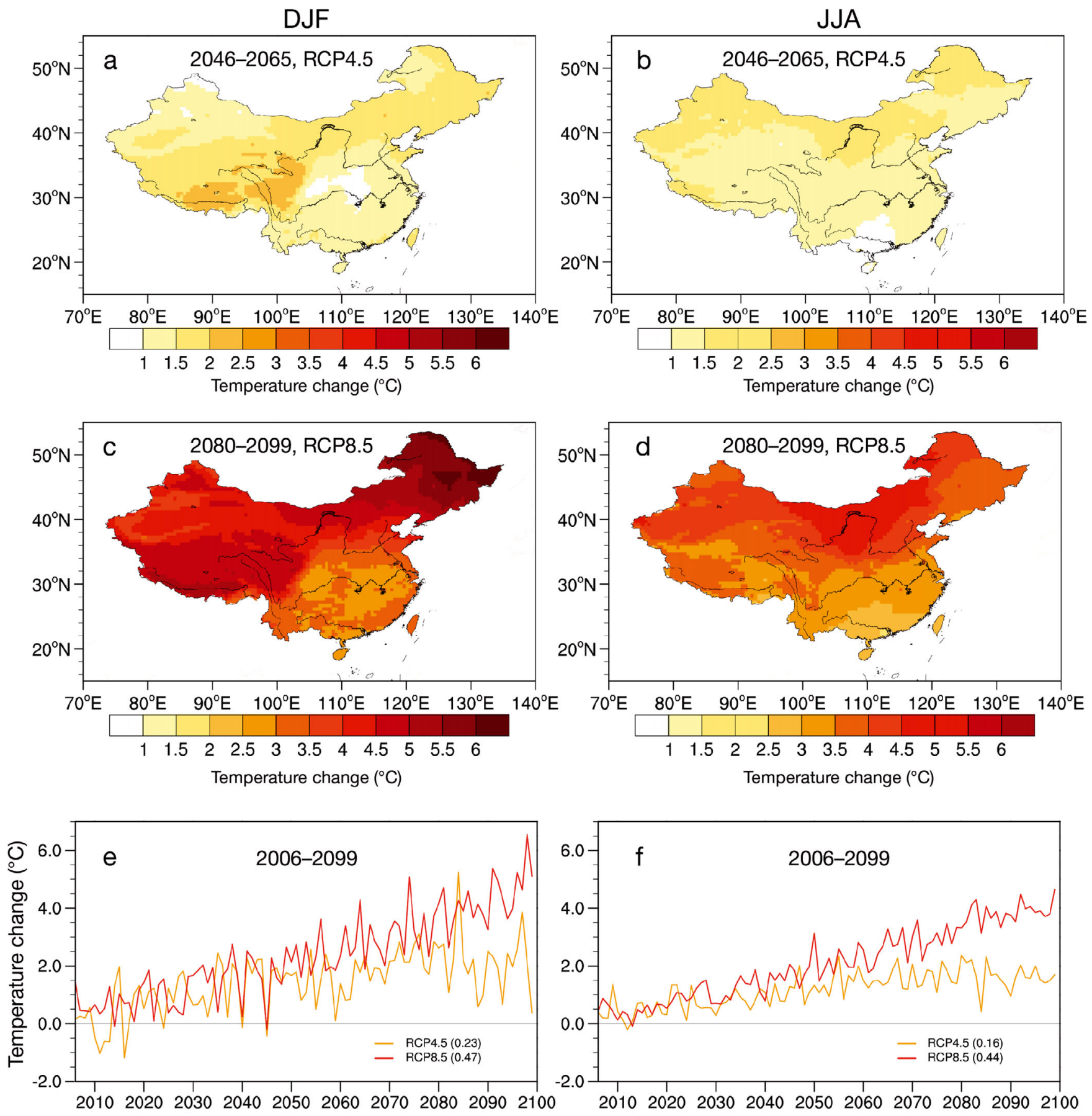

Fig. 4. Temperature changes over China compared to 1986-2005 ( ${ }^{\circ} \mathrm{C}$ ). (a) DJF and (b) JJA for RCP4.5 mid-century (2046-2065); (c) DJF and (d) JJA for RCP8.5, end of century (2080-2099); (e) DJF and (f) JJA for the China average during the 21st century. Parentheses: trends of changes (unit: ${ }^{\circ} \mathrm{C} 10 \mathrm{yr}^{-1}$ ). The changes are all significant at $95 \%$ confidence level

found in the annual mean changes (figures not shown; see Gao et al. 2013 for more detail).

The greater warming in DJF can also be observed when comparing Fig. 4e,f. The temperature increase under RCP8.5 is almost linear throughout the 21st century, with linear trends for DJF and JJA of 0.47 and $0.44^{\circ} \mathrm{C}$ decade ${ }^{-1}$, respectively. A temperature stabilization is found under the RCP4.5 scenario in the second half of the century, with overall century trends of 0.23 (DJF) and $0.16^{\circ} \mathrm{C}$ decade $^{-1}$ (JJA), respectively. All the changes in Fig. 4 are statistically significant at the $95 \%$ confidence level. 

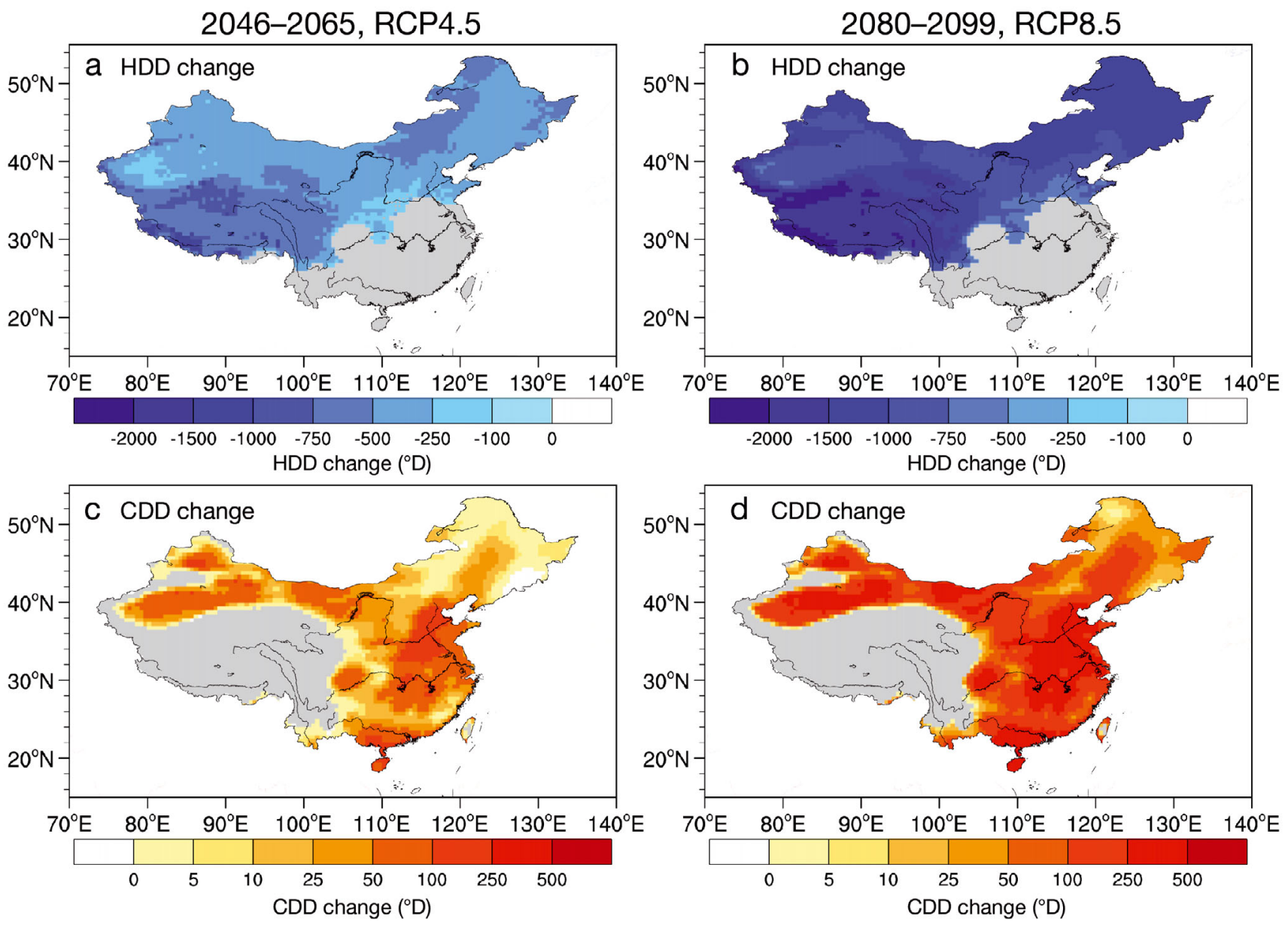

Fig. 5. Change of (a,b) HDD and (c,d) CDD compared to 1986-2005. (a) HDD and (c) CDD for RCP4.5 mid-century (2046-2065); (b) HDD and (d) CDD for RCP8.5 end of century. Gray: no heating or cooling. In all colored areas, the changes are significant at $95 \%$ confidence level, except when they are $<5^{\circ} \mathrm{D}$ in (c)

\subsection{Future changes of HDD and CDD}

The spatial distributions of the projected changes in HDD and CDD for the RCP4.5 mid-21st century and RCP8.5 end of century are presented in Fig. 5. A predominant decrease of HDD is projected in the future, larger in the high-latitude and high-elevation areas with cold climate conditions, consistent with the maximum warming there. The decrease of HDD for the RCP8.5 late 21st century is clearly much larger than the mid-century RCP4.5, e.g. in the range of 500 to 750 (mid-century RCP4.5) and 1000 to $1500^{\circ} \mathrm{D}$ (end of century RCP8.5) over most of the Northeast. The largest decreases in HDD, with maxima of up to -1000 and $-2000^{\circ} \mathrm{D}$, are found over the Tibetan Plateau.

An increase of CDD throughout the 21st century is found over most of China except over the cold or cool regions of the Tibetan Plateau and some other mountainous regions (Tianshan Mountain in the northwest and Changbai Mountain in the northeast) (Fig. 5c,d).
In eastern China, CDD increases mostly in the range of $100-250$ and $250-500^{\circ} \mathrm{D}$ for the 2 time slices are found in the area extending from northern China to the southern extent of the Yangtze River Basin and in Hua'nan. Larger increases are mainly found in the basins of western China, most notably in the heavily populated Sichuan Basin.

The temporal evolution of mean HDD and CDD changes over China under the RCP4.5 and RCP8.5 scenarios are presented by the solid lines in Fig. 6. In general, the changes in HDD and CDD show small differences between RCP4.5 and RCP8.5 before the 2040s, in agreement with the low scenario dependence of climate change in the early 21st century (IPCC 2013). The changes are more pronounced under the RCP8.5 compared to RCP4.5 in latter half of the century, and the decrease in HDD is much larger than that of CDD. In the latter part of the century, the decrease and increase in HDD and CDD, respectively, stabilize at $\sim 450^{\circ} \mathrm{D}$ and $30^{\circ} \mathrm{D}$ in the 


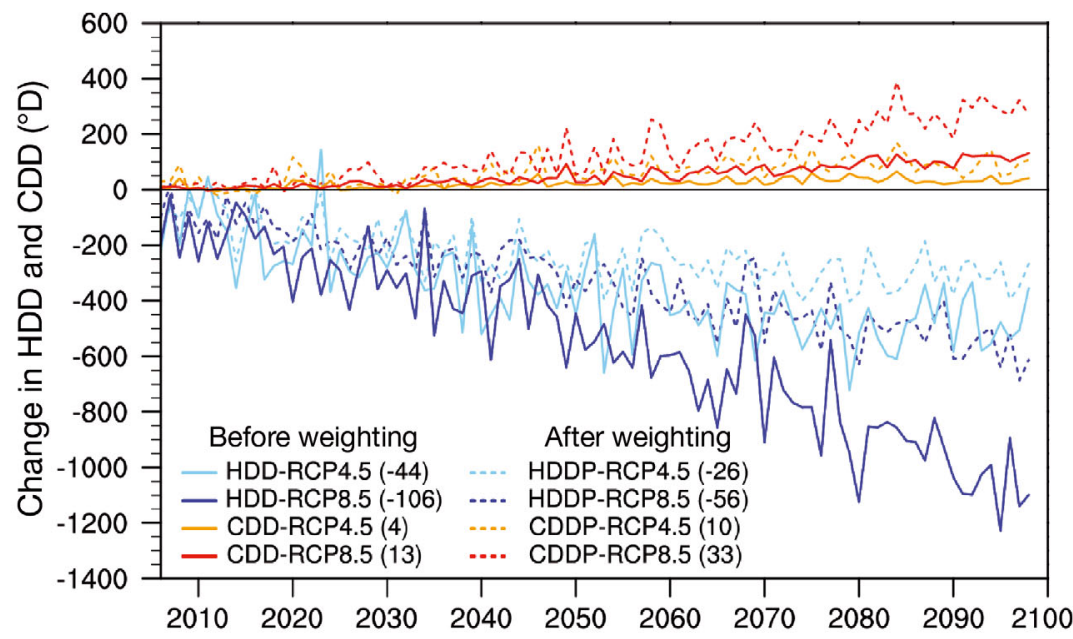

Fig. 6. Changes of HDD and CDD averaged over China in the 21st century (2006-2099). The solid lines are before and dashed lines are after the population weighting. The trends of the changes are presented in parentheses (unit: ${ }^{\circ} \mathrm{D}$ decade ${ }^{-1}$; all significant at $95 \%$ confidence level)

RCP4.5 scenario, while the changes are almost linear in $\mathrm{RCP} 8.5$, reaching values of up to $-1100^{\circ} \mathrm{D}$ and $100^{\circ} \mathrm{D}$, respectively, following the design of the scenarios (Moss et al. 2010). The linear trends of the HDD decrease are much larger (by a factor of $\sim 10$ ) compared to the trends of CDD increase under both scenarios.

\subsection{Changes of population weighted HDD and CDD}

We now turn our attention to the effect of population weighting on the CDD and HDD projections. Spatial distribution of the HDDP and CDDP changes for the mid-century RCP4.5 and late century RCP8.5 are presented in Fig. 7. Large differences can be found when comparing Fig. 7 to Fig. 5. In general, the changes of HDDP and CDDP are more pronounced in the regions with higher population density (Fig. 1). For HDDP, the most noticeable difference compared to HDD is the increase in northern China despite the warming there. This increase is due to the large future population increase projected over the region (Fig. 1c,d), which overwhelms the effect of climate change. Northern China is also the region with largest CDDP increase in both mid-century RCP4.5 and late century RCP8.5. While the changes for HDD over the Tibetan Plateau and CDD over the northwest are large, much lower changes in HDDP and CDDP can be found over these regions characterized by very low population density.
When averaged over the different provinces, in both scenarios, large decreases in HDDP and smaller increases in CDDP dominate over northern and western China (Fig. 8); however, increases in HDDP are found in the northern provinces (cities) of Beijing, Tianjin, Hebei, Shandong and Henan in eastern China, due to the population increases there. The increases in CDDP over these provinces are even more pronounced than in southern China due to the compounded effect of summer warming and population increase, indicating a strong increase of energy demand over these regions.

Regional mean HDDP and CDDP changes over China in the 21st century are given by the dashed lines in Fig. 6. The trends in general follow the un-weighted HDD and CDD (solid lines) ones, but the population weighting dramatically affects the relative magnitude of the HDDP and CDDP changes. In fact, while before the weighting the decrease in HDD is much larger than the increase in $\mathrm{CDD}$, after the population weighting the 2 trends are more similar in magnitude. For example, in the RCP8.5 scenario, the decrease in HDD and increase in CDD change from 1000 and $100^{\circ} \mathrm{D}$, respectively, in the un-weighted case to around 500 and $300^{\circ} \mathrm{D}$ after the weighting. This is because the areas undergoing the increase in CDD, mostly warm areas in the plains, are expected to undergo much more pronounced population growth than those exhibiting a decrease in HDD (cold and mountainous areas).

Changes in HDDP and CDDP for the mid- and late 21st century over the whole of China, expressed in degree days and percent of present day values, are provided in Table 1 . The changes in HDDP are 3-fold higher than the changes in CDDP in the mid-century under the 2 scenarios and in the late century under RCP4.5, but only 2-fold higher in the late century RCP8.5. By the end of the century, HDDP decreases by about 23 and $39 \%$, while CDDP increases by factors greater than 1.3 and 3.7 under RCP4.5 and RCP8.5, respectively. Therefore, mitigation from the higher emission scenario RCP8.5 to the lower RCP4.5 shows more effect on CDDP (thus the cooling energy demand) than HDDP, mostly as a result of the changes in population densities. It is interesting to note that the sum of HDDP and CDDP shows only relatively small differences between the 2 scenarios 

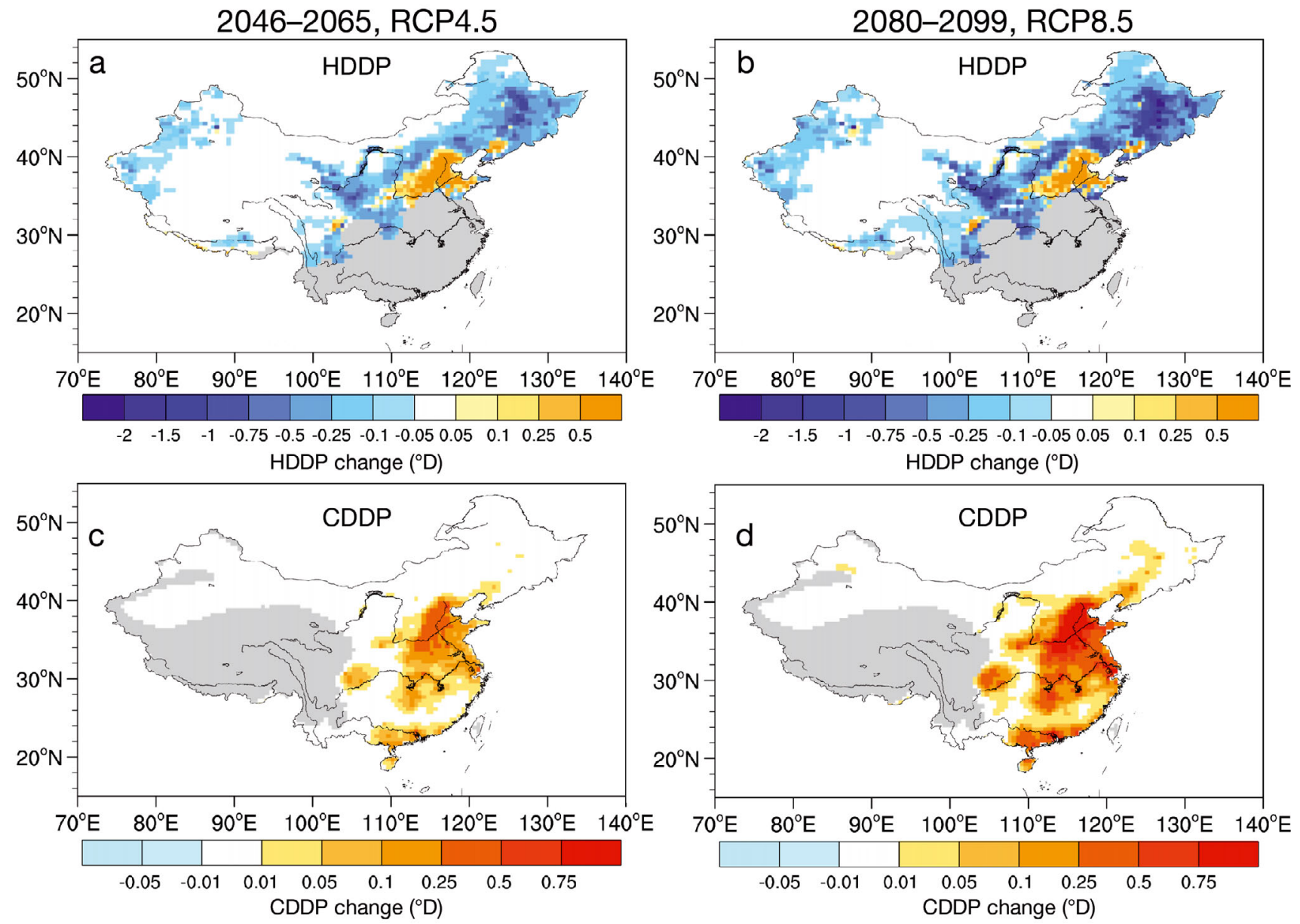

Fig. 7. Same as Fig. 5, but for population weighted HDD and CDD (HDDP and CDDP, respectively). In all colored areas, the changes are significant at the $95 \%$ confidence level

and across time slices, with values ranging from -189 to $-265^{\circ} \mathrm{D}$ (or about $-15 \%$ ). The negative value of this sum implies a general reduction in future energy demand in the household sector.

The annual cycle of the changes in HDDP and CDDP averaged over China for mid-century RCP4.5 and late century RCP8.5 as well as their corresponding values in the present day and the 2 future time slices are shown in Fig. 9. A general decrease in HDDP in the cold half of the year and an increase in CDDP in the warm half is found (Fig. 9a). In addition, the decrease in HDDP in winter and the increase in CDDP in summer for the late century RCP8.5 are 2- to 3-fold and 3- to 4-fold larger than for the mid-century RCP4.5, respectively. Compared to the present day (Fig. 9b), the peak of HDDP in winter becomes less pronounced in the future, while the peak of CDDP in summer is amplified, with this shift being more pronounced in the RCP8.5 than the RCP4.5.

\subsection{Sensitivity of HDD and CDD to the reference temperature}

In this section, we briefly discuss the sensitivity of the calculations for HDD and CDD to the values of reference temperatures. In particular, we test values in line with those presently used in economically advanced countries (USA and Europe), i.e. $18^{\circ} \mathrm{C}$ for heating and $22^{\circ} \mathrm{C}$ for cooling (referred to as HDD18 and CDD22, respectively).

The spatial distributions of the present-day HDD18 and CDD22 are similar to those for HDD and CDD but with much larger values, particularly for CDD22 (figures not shown for brevity). Population weighted China-wide annual mean HDD18P and CDD22P are 2562 and $321^{\circ} \mathrm{D}$, respectively, which are about 2 - and 4.5-fold higher than HDDP and CDDP using the current reference temperatures $\left(1366\right.$ and $71^{\circ} \mathrm{D}$, respectively). Differences between HDD18P and HDDP can be found in all months (Fig. 10a). HDD18P in the 

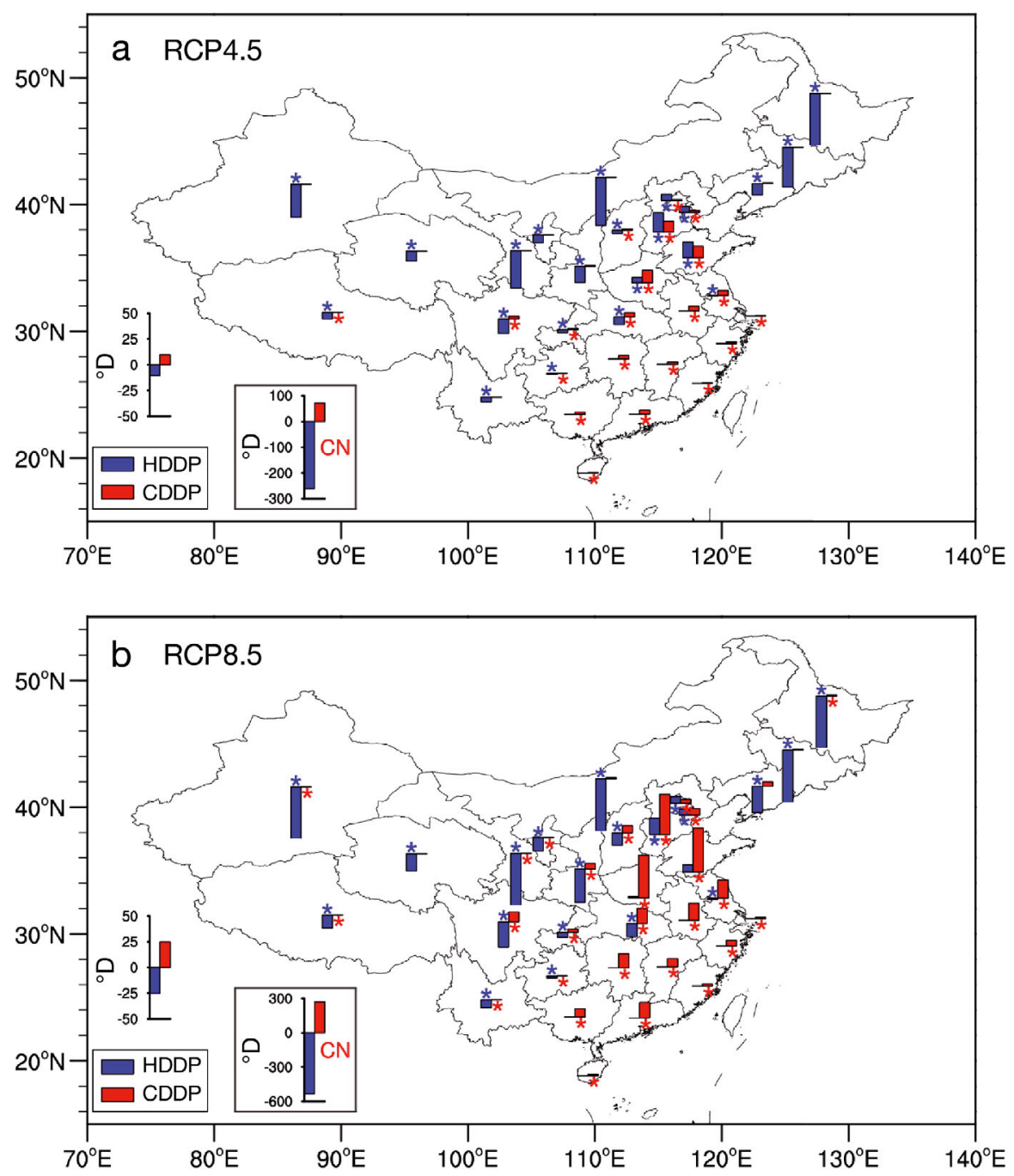

Fig. 8. Changes in HDDP and CDDP in different provinces (scale at left of panel) and the whole country (marked with $\mathrm{CN}$ ) for (a) RCP4.5 mid-century (2046-2065) and (b) RCP8.5 end of century (2080-2099). Asterisks indicate significance at the $95 \%$ confidence level winter months (from November to March) is 2-fold greater than HDDP, and the differences between HDD18P and HDDP can be even larger in the seasonal transition months. CDD22P in JJA is 4- to 8-fold higher than CDDP and is also larger in the transition months.

The annual cycle of the changes in HDD18P/CDD22P averaged over China in the future compared to the present-day HDDP/CDDP, i.e. assuming that in the future the heating and cooling policies in China will be similar to those currently used in Europe and the USA, is shown in Fig. 10b. Compared to the changes of HDDP and CDDP (Fig. 9a), the most important effect of the future implementation of the different heating and cooling reference temperatures is that the change in heating demand becomes positive in all months. A much greater increase in cooling demand is also evident when comparing future CDD22P with present CDDP for both scenarios. As a result, the sum of the HDD18P and CDD22P changes (compared to present-day HDDP and CDDP) is positive and in fact rather large and with relatively small variations across scenarios and time slices: 1077 to $1121^{\circ} \mathrm{D}$ (or $\sim 80 \%$ ) (Table 1 ). This illustrative example thus shows how future changes in heating and cooling policies can have dominant effects on the overall energy demand in China.
Table 1. Changes in the annual mean HDDP, HDD18P and CDDP, CDD22P in the mid (2046-2065) and end (2080-2099) of the 21st century under RCP4.5 and RCP8.5 relative to the present day (1986-2005) HDDP and CDDP over China

\begin{tabular}{|lcccc|}
\hline & \multicolumn{2}{c}{ Mid-21st } & \multicolumn{2}{c|}{$\begin{array}{c}\text { End of 21st } \\
\text { century }\left({ }^{\circ} \mathrm{D} / \%\right)\end{array}$} \\
& century $\left({ }^{\circ} \mathrm{D} / \%\right)$ & \multicolumn{2}{c}{ R } & \\
& RCP4.5 & RCP8.5 & RCP4.5 & RCP8.5 \\
\hline HDDP & $-261 /-19$ & $-370 /-27$ & $-311 /-23$ & $-535 /-39$ \\
CDDP & $72 / 101$ & $128 / 179$ & $95 / 133$ & $270 / 379$ \\
HDDP+CDDP & $-189 /-13$ & $-242 /-17$ & $-216 /-15$ & $-265 /-19$ \\
HDD18P & $749 / 55$ & $590 / 43$ & $672 / 49$ & $312 / 23$ \\
CDD22P & $422 / 594$ & $524 / 738$ & $449 / 632$ & $745 / 1049$ \\
HDD18P+CDD22P & $1171 / 81$ & $1114 / 76$ & $1121 / 78$ & $1077 / 75$ \\
\hline
\end{tabular}

\section{CONCLUSIONS AND DISCUSSION}

In this paper, future changes in HDD/ HDDP and CDD/CDDP in the 21st century over mainland China under different GHG forcing scenarios are investigated using the regional climate model RegCM4 driven by the BCC_CSM1.1 global climate model. The climate indicators are further weighted by present day and projected population densities in order to provide a first-order assessment of potential energy demand. Our main conclusions and considerations can be summarized as follows: 

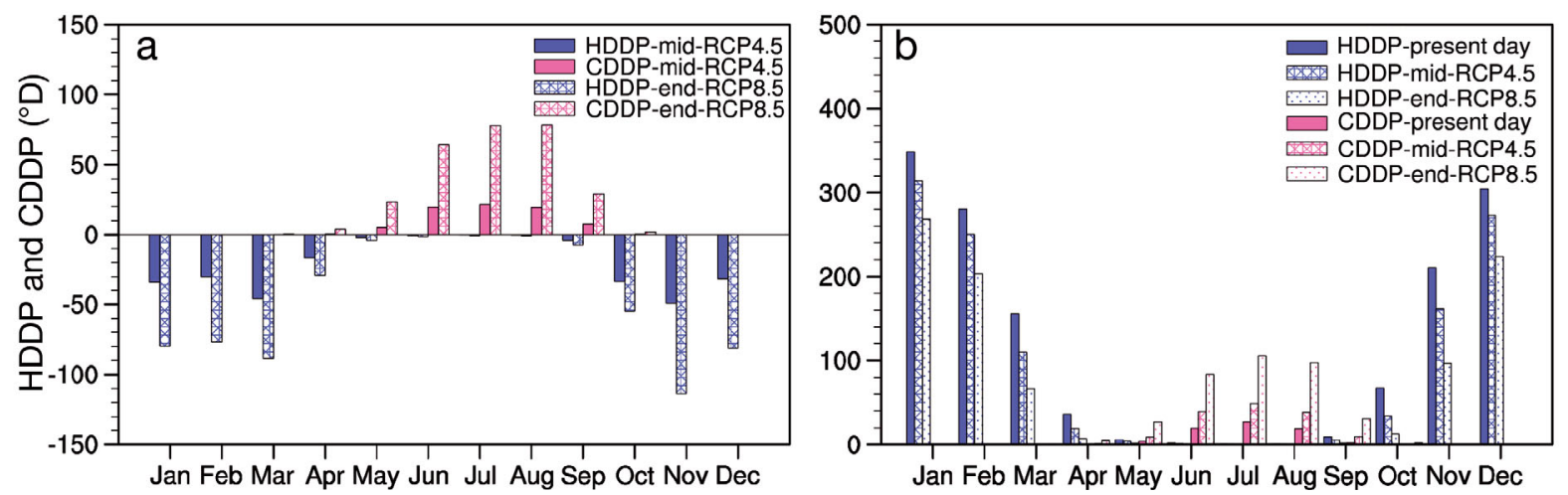

Fig. 9. Annual cycle of (a) China-mean changes of HDDP and CDDP in the mid (2046-2065) and end (2080-2099) of the 21st century and (b) HDDP and CDDP for the present day (1986-2005), RCP4.5 mid-21st century and RCP8.5 end of 21st century. The changes are all significant at the $95 \%$ confidence level
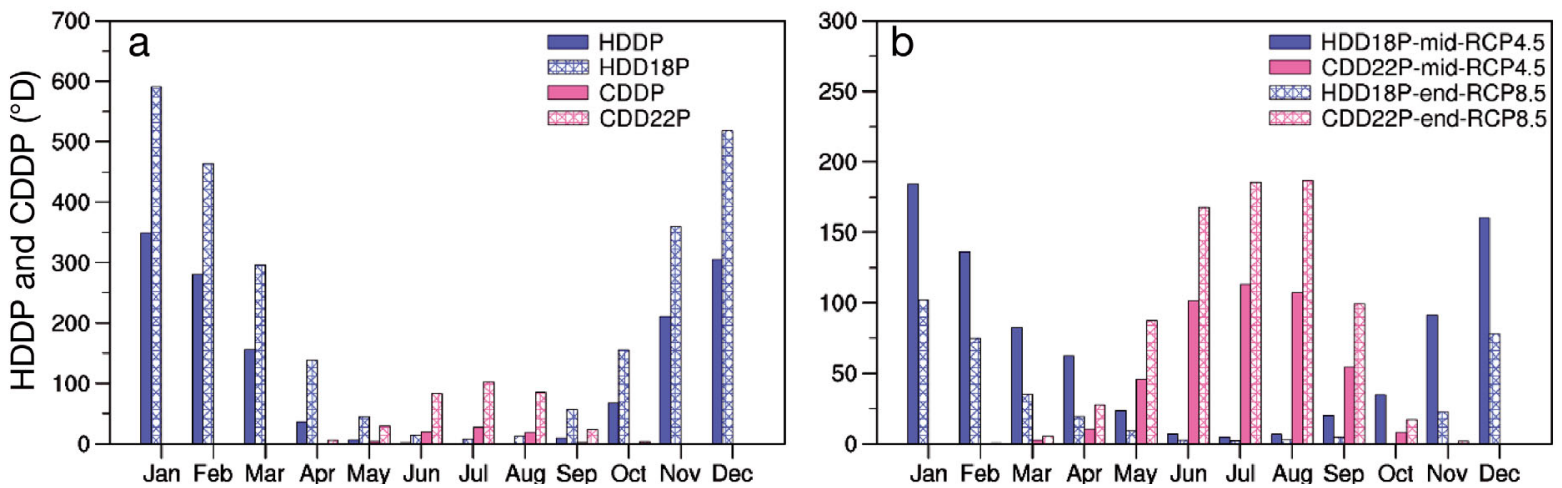

Fig. 10. Annual cycle of (a) China-mean HDDP, HDD18P and CDDP, CDD22P (see text) for the present day period (1986-2005) and (b) future changes of HDD18P and CDD22P compared to present day HDDP and CDDP, respectively, for the RCP4.5 midcentury (2046-2065) and RCP8.5 end of century (2080-2099) periods. The changes are all significant at the $95 \%$ confidence level

(1) The model can reproduce well the present-day mean climatology, seasonal cycle, and interannual variability of HDD and CDD over China, along with the trend of HDD during the present day period. A lower performance is found for the present-day trend of CDD over the region. More generally, a better model performance is found for HDD compared to CDD.

(2) A substantial decrease in HDD and increase in CDD is found in the future in response to the GHGinduced warming, with more pronounced changes under the RCP8.5 than the RCP4.5 scenario, in particular during the second half of the 21 st century. When averaged over the whole of China, the decrease in $\mathrm{HDD}$ is larger than the increase in CDD; however, there is a distinct regional variability in these trends. For example, over eastern China, the change in HDD shows a latitudinal distribution with a larger decrease in the north. The increase in CDD is more pronounced in the eastern plain areas and the southern coasts.

(3) Population weighting substantially affects the changes in HDD and CDD, even reversing its sign over some regions of northern China, where both HDDP and CDDP increase. This illustrates the importance of adding a metric of exposure (in this case population density) to estimates of climate change impacts on energy demand.

(4) Assuming the same energy demand for changes in HDDP and CDDP, the future total energy consumption in China in the household sector shows a decrease of about $15 \%$. However, while most of the cold part of the country benefits from a lower energy use for heating, the southern part experiences an increase in energy demand for cooling. This will lead to the need for additional transport of coal, oil, and electricity, etc., from the north to the south. Energy consumption will also show changes in seasonal distribution, with greater demand in the summer and lower in the winter.

(5) For our calculations of HDDP and CDDP, we used the standards that are currently used in China, with heating restricted to northern China and starting only when the temperature drops to $5^{\circ} \mathrm{C}$, and 
cooling starting when temperatures exceed $26^{\circ} \mathrm{C}$. With economic growth, these reference temperatures will most likely move closer to the values currently used in economically advanced countries, $18^{\circ} \mathrm{C}$ and $22^{\circ} \mathrm{C}$ for heating and cooling, respectively. Sensitivity of the HDD18P and CDD22P calculations to the use of these values shows that potentially large increases in energy demand $(\sim 80 \%)$ are expected in the future in China under this scenario of change in reference temperature, illustrating the dominant role that changes in policy can have regarding energy demand.

Our results have important implications for energy management policies in the country. Clearly, the issue of future energy demand due to changes in HDD and CDD is complex and multifaceted, with a strong dependence on the spatial variability of climate change and population dynamics. Due to the limited scope of this paper, we only focused on a small number of RCM simulations available with 1 model. More studies are thus needed to better address the uncertainties in the climate scenario projections through ensembles of RCM simulations. In addition, we adopted simple assumptions for the relation between degree days, population and energy demand. However, there is the need to measure the direct relation between degree days and energy consumption (Isaac \& van Vuuren 2009) and to better account for future changes in economic conditions and population amount and distribution (Isaac \& van Vuuren 2009). Future work will thus go in the direction of providing more comprehensive assessments of energy demand within a multi-model framework (e.g. CORDEX; Giorgi et al. 2009) incorporating more detailed socio-economic components.

Acknowledgements. This research was jointly supported by R\&D Special Fund for Public Welfare Industry (meteorology) (GYHY201306019) and National Natural Science Foundation of China (41375104).

\section{LITERATURE CITED}

CCSNARCC (Committee for China's Second National Assessment Report on Climate Change) (2011) The Second National Assessment Report on Climate Change. Science Press, Beijing

Chen W, Liu JJ (2009) Future population trends in China: 2005-2050. Monash University, Centre of Policy Studies and the Impact Project, Melbourne

> Chen L, Fang XQ, Li S (2007) Impacts of climate warming on heating energy consumption and southern boundaries of severe cold and cold regions in China. Chin Sci Bull 52: 2854-2858

Christenson M, Manz H, Gyalistras D (2006) Climate warm- ing impact on degree-days and building energy demand in Switzerland. Energy Convers Manag 47:671-686

Gao XJ, Zhao ZC, Ding YH, Huang RH, Giorgi F (2001) Climate change due to greenhouse effects in China as simulated by a regional climate model. Adv Atmos Sci 18: 1224-1230

Gao XJ, Shi Y, Giorgi F (2011) A high resolution simulation of climate change over China. Sci China Earth Sci 54: $462-472$

> Gao XJ, Shi Y, Zhang DF, Wu J, Giorgi F, Ji ZM, Wang YG (2012) Uncertainties of monsoon precipitation projection over China: results from two high resolution RCM simulations. Clim Res 52:213-226

Gao XJ, Wang ML, Giorgi F (2013) Climate change over China in the 21st century as simulated by BCC_CSM1.1RegCM4.0. Atmos Ocean Sci Lett 6:381-386

Giorgi F, Jones C, Asrar G (2009) Addressing climate information needs at the regional level: the CORDEX framework. WMO Bull 58:175-183

- Giorgi F, Coppola E, Solmon F, Mariotti L, Sylla BM, Bi XQ (2012) RegCM4: model description and illustrative basic performance over selected CORDEX domains. Clim Res 52:7-29

Guo DL, Wang HJ (2013) Simulation of permafrost and seasonally frozen ground conditions on the Tibetan Plateau, 1981-2010. J Geophys Res Atmos 118:5216-5230

> Guttman NB (1983) Variability of population-weighted seasonal heating degree days. J Clim Appl Meteorol 22: 495-501

IPCC (2013) Climate Change 2013: the physical science basis. In: Stocker TF, Qin DH, Plattner GK, Tignor M and others (eds) Contribution of Working Group I to the 5th Assessment Report of the Intergovernmental Panel on Climate Change. Cambridge University Press, Cambridge

> Isaac M, van Vuuren DP (2009) Modelling global residential sector energy demand for heating and air conditioning in the context of climate change. Energy Policy 37:507-521

Ji ZM, Kang SC (2015) Evaluation of extreme climate events using a regional climate model for China. Int J Climatol 35:888-902

Ju LX, Wang HJ, Jiang DB (2007) Simulation of the Last Glacial Maximum climate over East Asia with a regional climate model nested in a general circulation model. Palaeogeogr Palaeoclimatol Palaeoecol 248:376-390

Kadioğlu M, Şen Z (1999) Degree-day formulations and application in Turkey. J Appl Meteorol 38:837-846

Labriet M, Joshi SR, Vielle M, Holden PB and others (2015) Worldwide impacts of climate change on energy for heating and cooling. Mitig Adapt Strategies Glob Change 20:1111-1136

> Li T, Zhou GQ (2010) Preliminary results of a regional airsea coupled model over East Asia. Chin Sci Bull 55: 2295-2305

Li XC, Bai ML, Yang J, Yu FM, Di RQ, Ma YF (2010) Impacts of climate warming on energy consumed in heating period in Hohhot. Adv Clim Chang Res 6:29-34 (in Chinese)

Lutz W, Sanderson W, Scherbov S (2008) The coming acceleration of global population ageing. Nature 451:716-719

MCPRC (Ministry of Construction of the People's Republic of China) (2003) Code for design of heating ventilation and air conditioning (GB50019-2003), 1893-1951. MCPRC, Beijing

Moss RH, Edmonds JA, Hibbard KA, Manning MR and others (2010) The next generation of scenarios for climate 
change research and assessment. Nature 463:747-756

New M, Lister D, Hulme M, Makin I (2002) A high-resolution data set of surface climate over global land areas. Clim Res 21:1-25

Quayle RG, Diaz HF (1980) Heating degree day data applied to residential heating energy consumption. J Appl Meteorol 19:241-246

Rehman S, Al-Hadhrami LM, Khan S (2011) Annual and seasonal trends of cooling, heating, and industrial degree-days in coastal regions of Saudi Arabia. Theor Appl Climatol 104:479-488

Ren YY, Ren GY, Qian HS (2009) Change scenarios of China's provincial climate-sensitive components of energy consumption. Geogr Res 28:36-44

Riahi K, Nakicenovic N (eds) (2007) Greenhouse gases integrated assessment. Technol Forecasting Soc Chang Spec Issue 74:873-1108

Roltsch WJ, Zalom FG, Strawn AJ, Strand JF, Pitcairn MJ (1999) Evaluation of several degree-day estimation methods in California climates. Int $\mathrm{J}$ Biometeorol 42: 169-176

Spinoni J, Vogt J, Barbosa P (2015) European degree-day climatologies and trends for the period 1951-2011. Int J Climatol 35:25-36

SSB (State Statistical Bureau) (2013) China Energy Statistical Yearbook 2013. China Statistics Press, Beijing

Sui Y, Lang XM, Jiang DB (2014) Time of emergence of climate signals over China under the RCP4.5 scenario. Clim Change 125:265-276

Tan BG, Tian Z, Liu KX, Li MC, Guo J, Xiong MM (2012) Annual variation characteristics of degree-days and the trend analysis in Tianjin. Renew Energy Resour 30: 102-105

UNFPA (United Nations Fund for Population Activities) (2010) State of world population. UNFPA, New York, NY

United Nations (2015) World population prospects: the 2015 revision, key findings and advance tables. UN Department of Economic and Social Affairs, Population Division, Working Paper No. ESA/P/WP.241, New York, NY

Editorial responsibility: Oliver Frauenfeld,

College Station, Texas, USA
Wang XM, Chen D, Ren ZG (2010) Assessment of climate change impact on residential building heating and cooling energy requirement in Australia. Build Environ 45: 1663-1682

Wu J, Gao XJ (2013) A gridded daily observation dataset over China region and comparison with the other datasets. Chin J Geophys 56:1102-1111

Wu TW, Yu RC, Zhang F, Wang ZZ and others (2010) The Beijing Climate Center atmospheric general circulation model: description and its performance for the presentday climate. Clim Dyn 34:123-147

> Wu J, Gao XJ, Giorgi F, Chen ZH, Yu DF (2012) Climate effects of the Three Gorges Reservoir as simulated by a high resolution double nested regional climate model. Quat Int 282:27-36

Xin XG, Wu TW, Li JL, Wang ZZ, Li WP, Wu FH (2013) How well does BCC_CSM1.1 reproduce the 20th century climate change over China? Atmos Oceanic Sci Lett 6:21-26

Xu Y, Gao XJ, Shen Y, Xu CH, Shi Y, Giorgi F (2009) A daily temperature dataset over China and its application in validating a RCM simulation. Adv Atmos Sci 26:763-772

You QL, Fraedrich K, Sielmann F, Min JZ and others (2014) Present and projected degree days in China from observation, reanalysis and simulations. Clim Dyn 43: 1449-1462

Yu ET, Wang HJ, Sun JQ (2010) A quick report on a dynamical downscaling simulation over china using the nested model. Atmos Ocean Sci Lett 3:325-329

Zhai PM, Pan X (2003) Trends in temperature extremes during 1951-1999 in China. Geophys Res Lett 30:1913-1916

Zhang DF, Shi Y (2012) Numerical simulation of climate changes over North China by the model RegCM3. Chin J Geophys 55:474-487

Zhang DF, Gao XJ, Ouyang LC (2008) Simulation of present climate over China by a regional climate model. J Trop Meteorol 14:19-23

Zhou TJ, Yu RC (2006) Twentieth century surface air temperature over China and the globe simulated by coupled climate models. J Clim 19:5843-5858

Submitted: June 10, 2015; Accepted: November 29, 2015

Proofs received from author(s): January 26, 2016 